Cómo citar este artículo en MLA: Zengotita, Alonso. "La incidencia social del arte: conservación y transformación en Freud y Nietzsche”. Escritos 27.59 (2019): 274-295. doi: http://dx.doi.org/10.18566/escr.v27n59.a04

Fecha de recepción: 19.03 .2019

Fecha de aceptación: 11.07.2019

\title{
La incidencia social del arte: conservación y transformación en Freud y Nietzsche
}

\author{
Social Impact of Art: Conservation and Transformation \\ in Freud and Nietzsche \\ A abrangência social da arte: conservação e transformação \\ segundo Freud e Nietzsche
}

\begin{abstract}
Alonso Zengotita ${ }^{1}$
RESUMEN

En el presente trabajo se buscará abordar la relación entre las obras de Nietzsche y Freud y el arte a partir de dos líneas de análisis: en primer lugar, el modo particular en que, para cada autor, se despliega la relación del arte con el plano social; en segundo lugar, que la noción misma de arte se halla íntimamente ligada al modo en que, para cada uno, se caracterizan la percepción y al concepto mismo de vida. Finalmente, se trazará una articulación entre ambas líneas analíticas: el modo particular en que
\end{abstract}

1 Doctor en Filosofía por la Universidad de Buenos Aires (Argentina). El artículo se enmarca en la investigación postdoctoral 'El poder y la resistencia: el abordaje de las derivas biopolíticas en las últimas obras de Esposito y Foucault a partir de la dinámica vital en Nietzsche y Freud', sustentada por Beca Postdoctoral Conicet 2016-19. Correo electrónico: alonsozengotita@gmail.com 
el arte es, para ambos autores, pensado en términos sociales, se sustenta -a través de la manera en que es concebida la percepción- a partir del concepto mismo de vida. Esta articulación permitirá fundamentar cómo es que Freud mantiene una relación sintónica con el arte clásico, mientras que la perspectiva nietzscheana, por el contrario, resulta sintónica con el arte de vanguardia.

Palabras clave: Arte, social, percepción, vida, transformación.

\begin{abstract}
Based on two lines of reasoning, the article addresses the relation of both the works of Nietzsche and Freud with art: Firstly, the way in which Freud and Nietzsche think art relates to the social realm; secondly, that the very idea of art is closely linked to the way in which each one considers that perception and the very idea of life are characterized. Bearing this in mind, the article, then, correlates both lines of reasoning: the way in which both thinkers consider art in social terms is based on the very idea of life. Such correlation makes possible to explain why Freud establishes a syntonic relation with classical art, whereas Nietzsche's view establishes a syntonic relation with avant-garde art.
\end{abstract}

Key words: Art, Society, Perception, Life, Transformation.

\title{
RESUMO
}

Esse artigo tratará a relação entre as obras de Nietzsche, Freud e a arte, a partir de duas perspectivas de análise: em primeiro lugar, o olhar singular de cada autor do modo como se desenvolve a relação da arte com o plano social. Em segundo lugar, que a definição de arte esteja ligada à caracterização da percepção e ao conceito de vida de cada autor. Finalmente, traçarei uma articulação entre as duas perspectivas de análise: o pensamento particular da arte em termos sociais dos dois autores se sustém na conceição da percepção baseada no conceito de vida. Essa articulação permitirá fundamentar como Freud mantém uma relação sintonizada com a arte clássica; enquanto a perspectiva nietzschiana, ao contrário, é afim à arte de vanguarda.

Palavras chave: arte, social, percepção, vida, transformação. 


\section{Introducción}

1 momento de abordarse las relaciones Nietzsche-Freud, la temática
del arte resulta un territorio poco explorado; esto puede deberse,
quizá, a que -comparativamente- la concepción de arte resulta mucho más nuclear en la obra nietzscheana que a la freudiana. Así, las relaciones entre Freud y Nietzsche han sido abordadas más centralmente en términos de su posición respecto a la filosofía (Granier, 1979; Boothby, 2001; Vázquez Rocca, 2005; Drivet, 2015), a la psicología (Golomb, Santaniello, Lehrer, 1999; Chapelle, 1993; García, 2001; Onfray, 2012), el concepto de lo vital (Faulkner, 2003; Almeida, 2005; Uribe, 2002; Reginster, 2006; Steineger, 2004; Vázquez Rocca, 2014), el poder (Butler, 2010; Rozitchner, 1982), entre otros. Incluso trabajos integrales sobre las relaciones entre Nietzsche y Freud (Gasser, 1997; Assoun, 2008; Ansell-Pearson, 1991) toman la relación desde lo artístico de modo tangencial ${ }^{2}$. En el presente trabajo se buscará abordar el modo en que el arte se articula, en Nietzsche y Freud, desde la perspectiva de la capacidad transformativa que el mismo presenta en relación con lo social. Esta modalidad de abordaje se fundamenta en que, para ninguno de los dos, el arte es pensado en términos solipsistas. En efecto, en Freud, si bien hay toda una línea de lectura relativa al arte que hace exclusivamente a la economía energética propia del individuo, esta nunca es pensada sino en función de qué lugar depara-como artista o como espectador- a través de una correlación social; esto se despliega asimismo en los ejemplos de análisis de obras artísticas, los cuales no apuntan, justamente -como buscaremos desarrollar- al concepto de arte en sí sino al sentido que una obra particular supone desde el (psico) análisis de su autor (lectura que, nuevamente, incorpora entonces el registro social, a través de la historia vivencial del autor). Con respecto a Nietzsche, buscaremos mostrar que desde El nacimiento de la tragedia -y en los desarrollos posteriores de su obra- el arte es considerado continuamente desde la capacidad de incidencia respecto de lo social. En el presente artículo buscaremos asimismo dar cuenta de los siguiente: si el arte presenta dichas relaciones para el plano social, esto

2 Es posible hallar incluso trabajos como el de Hanze (2003) que toman la relación de Freud y Nietzsche con la literatura, pero desde el punto de vista de la sublimación en términos de capacidad vital, o el de Lazcano (2013), que analiza el lugar de la música en la obra de ambos autores, pero desde el punto de vista de una resistencia freudiana a la lectura de Nietzsche. 
se sustenta, de modo estructural, en que no existe -para ninguno de los dosuna caracterización propia y exclusiva del plano estético. En efecto, a través del modo en que es conceptualizada, para cada autor, la percepción, se trazará una directa articulación entre dicha capacidad artística y el modo en que lo vital es pensado. Dicho de otro modo, solo desde el concepto mismo de vida que cada autor despliega, el lugar del arte -articulado mediante la caracterización de la percepción- puede ser comprendido en su potencial social.

\section{Nietzsche: la función social del arte en Die Geburt der Tragödie}

Primera obra nietzscheana publicada, El nacimiento de la tragedia en el espíritu de la música (Die Geburt der Tragödie aus dem Geiste der Musik), de 1872, trata sobre la tragedia ática, su origen y desaparición, desde una interpretación radicalmente divergente a la sostenida canónicamente por sus contemporáneos ${ }^{3}$. En esta interpretación, resulta fundamental el rol que juega el modo en que Nietzsche considera el despliegue vital en términos sociales a partir del arte.

Ya en el "Prólogo a Richard Wagner", que encabeza la obra, se destaca la relación entre arte y vida: “(...) el arte es la vocación más importante y la actividad esencialmente metafísica de la vida (...)." (Nietzsche, "Prólogo" 22). Dos señalamientos fundamentales se muestran aquí: el arte, en tanto actividad metafísica y "vocación más importante" (wichtigste Berufung), dispone la proyección hacia un plano separado de lo vital en tanto físico ${ }^{4}$, la cual supone la actividad primera, esencial, humana. Son dos los principios a partir de los cuales Nietzsche encuentra, en el arte griego, la posibilidad de dicha proyección vital: "Apolo y Dionisos, esos dos dioses del arte, son los que despiertan entre

3 Para ver en mayor profundidad la temática relativa a dicha polémica, $c f r$. Calder, 'El debate Wilamowitz-Nietzsche: nuevos documentos y una reevaluación'; asimismo Sweet, 'The Birth of 'The Birth of Tragedy".

4 Como quedará patente más adelante, la noción a la que apunta Nietzsche en esta obra al referirse al plano de lo físico -o sea, aquello de lo cual se produce, vía arte, la proyección a un 'más allá' - es el plano de la existencia del hombre. 
nosotros la idea del extraordinario antagonismo, tanto de origen como de fin, en el mundo griego, entre el arte plástico apolíneo y el arte desprovisto de formas, la música, el arte de Dionisos." (23). El principio apolíneo, principio de la forma plástica y del ensueño, es aquel de la "apariencia radiante"; allí el artista halla la serenidad en el reinado del principium individuationis, es decir, la individualidad sostenida en la perfección de la forma. Ahora bien, como Nietzsche resalta, "la vida más intensa de esta realidad de ensueño nos deja aún el sentimiento confuso de que no es más que fuego fatuo." (24). Es el segundo principio artístico quien conduce a la esencia por detrás de la apariencia: la embriaguez propia de la orgía báquica prefigura el encuentro con el fondo primordial de la vida, donde "cada uno se siente no solamente integrado, reconciliado, fundido, sino uno, como si se hubiera desgarrado el velo de Maia y sus pedazos revoloteasen ante la misteriosa Unidad primordial [Ür-eine]" (28). El carácter central que el arte presenta respecto a la vida se fundamenta en que los griegos
(...) han llegado hasta el fondo de las cosas con mirada decidida; (...) Bajo la influencia de la verdad contemplada, el hombre no percibe ya nada más que lo horrible y absurdo de la existencia (...) Y en este peligro inminente de la voluntad, el arte avanza como un dios salvador que trae el bálsamo saludable: él solo tiene el poder de transmutar ese hastío en imágenes que ayuden a soportar la vida (56-57).

La importancia social del arte es, entonces, de enorme intensidad y alcance, pues es capaz de transmutar el hastío en un imaginario que permite soportar la existencia dentro de la polis helénica ${ }^{5}$ : constituye lo social porque hace soportable la existencia individual, pero asimismo unifica dionosíacamente. La tragedia ática, que sintetiza ambas fuerzas, es la más alta producción artística griega: esa socialización que implica el espectáculo provee de la máxima potencia transformativa. Ahora bien, en tanto la actividad artística hace soportable a la existencia, no supone una transformación de la misma, sino su redención. Dicha redención se produce, así, en una transformación de la estética de la existencia: el impulso apolíneo lleva a un mundo de

5 La tragedia resulta así el modo de redención vital por excelencia, la 'suprema consolación metafísica’ de la existencia (Sokel 502). 
ensueño, a la perfección de la forma; el impulso dionisíaco, a la ruptura del principium individuationis y a la reconciliación mediante la falta de forma de la música, en "la misteriosa Unidad primordial". La transmutación resulta así, eminentemente, transmutación de la imagen propia de la existencia.

\section{Freud: principios del placer y de realidad en reconciliación artística}

En Freud, la cuestión del arte se encuentra articulada de modo directo al concepto de sublimación (Sublimierung). Junto a la represión y la perversión, Freud establece la sublimación como una de las tres posibles modalidades de elaboración posterior de la sexualidad infantil. La sublimación es definida como una "desviación de las fuerzas pulsionales sexuales de sus metas, y su orientación hacia metas nuevas", a través de la cual "se adquieren poderosos componentes para todos los logros culturales". (Freud, "Tres ensayos" 161), logros entre los cuales se halla la actividad artística.

Según Freud, "nosotros -el escritor y el analista- probablemente bebemos de la misma fuente, trabajamos sobre el mismo objeto, cada uno con un método diferente" (Gay 361-362). Ese objeto es el inconsciente, el cual es abordado psicoanalíticamente en la labor clínica, mientras que el escritor bucea en su propio inconsciente, dándole forma a sus hallazgos en términos de obra artística ${ }^{6}$. La propia obra de arte presenta una estructura analizable a la manera de un sueño o un lapsus: hay allí un contenido latente pasible de ser desentrañado mediante técnicas psicoanalíticas -en tanto resulta producto de los propios impulsos inconscientes del $\operatorname{artista}^{7}$. Ahora bien, desde Freud, aquello que provee a la obra de su carácter artístico -y que hace a su autor artista- es la capacidad de incidencia social que presenta. Al respecto, Freud afirma que

6 Al respecto, cfr. "La Gradiva de Jensen”. En Sigmund Freud. Obras completas. Buenos Aires: Amorrortu, 1992.

7 Cfr. "Un recuerdo infantil de Leonardo Da Vinci". En Sigmund Freud. Obras completas. Buenos Aires: Amorrortu, 1992. 
el arte logra por un camino peculiar una reconciliación del principio del placer y el principio de realidad. El artista (...) da libre curso en la vida de la fantasía a sus deseos eróticos y de ambición. Pero él encuentra el camino de regreso desde ese mundo de fantasía a la realidad; lo hace merced a particulares dotes, plasmando sus fantasías en un nuevo tipo de realidades efectivas que los hombres reconocen como una copias valiosas de la realidad objetiva misma (Freud, "Formulaciones" 229).

El artista es, entonces, aquel que es incapaz de proyectar sobre la realidad sus deseos de modo directo y logra superar dicha coartación indirectamente: plasmándolos en obras artísticas, es decir, reconocidas por otros como valiosas. De este modo,

lo que el artista busca es en primer lugar autoliberación, y la aporta a otros que padecen de los mismos deseos retenidos al comunicarles su obra. (...) No le resulta difícil al psicoanálisis pesquisar, junto a la parte manifiesta del goce artístico, una parte latente, pero mucho más eficaz, que proviene de las fuentes escondidas de la liberación de lo pulsional (Freud, "El interés” 189-190).

Junto al goce de la obra artística misma, lo que fundamentalmente se logra a través del arte es autoliberación: tanto para el espectador como para el creador, de lo que se trata es de liberar potencia pulsional coartada; esos deseos no satisfechos a través de un contacto directo con la realidad-deseos eróticos, de ambición- encuentran satisfacción mediante el rodeo dado en el plano artístico.

Ahora bien, será a partir de la distinción que Freud marca entre un goce artístico y la liberación de lo pulsional que se buscará poner en consonancia el modo en que el arte es concebido por Nietzsche.

En términos de la liberación de lo pulsional, es posible trazar una amplia convergencia: en ambos el arte supone una vía para la satisfacción de impulsos, satisfacción imposibilitada por la vía de la existencia misma: en Nietzsche, una existencia "horrible y absurda"; en Freud, una existencia que impide, de modo directo, satisfacer deseos "eróticos y de ambición".

En Nietzsche, el goce artístico implica una función social de importancia eminente: desde las sensaciones despertadas por el mundo de ensueño apolíneo 
y la embriaguez báquica se producen "imágenes que ayudan a soportar la vida" (Nietzsche, "El nacimiento" 57). El goce artístico supone así una verdadera transmutación: lo "horrible y absurdo" de la existencia resulta así redimido. En ese carácter auténticamente metafísico, la importancia del arte resulta verdadero fundamento de lo social mismo.

Por otra parte, ¿cuál es el la magnitud de incidencia social que Freud otorga a ese goce artístico?

Para responder esta pregunta se abordará el paradigmático texto El malestar en la cultura. Allí, Freud se interroga por las posibles vías que el hombre tiene para mitigar los diversos tipos de sufrimiento que se le presentan en su transcurso vital. Una de ellas, preponderante, consiste en el autogobierno sobre las propias pulsiones: cuando estas pulsiones no son satisfechas, el sufrimiento resulta mucho menor que en el caso de pulsiones que no han sido inhibidas. Sin embargo, existe una evidente consecuencia: la reducción de las posibilidades de goce, en tanto "el sentimiento de goce provocado por la satisfacción de una pulsión silvestre, no domeñada por el yo, es incomparablemente más intenso que el obtenido a partir de una pulsión enfrenada" (79).

Otra técnica para la evitación del sufrimiento es aquella de la sublimación: aquí, se trasladan las metas pulsionales de modo tal que "no puedan ser alcanzadas por la denegación del mundo exterior" (79). Esto se logra al poder elevar la ganancia de placer psíquico a través de actividades psíquicas e intelectuales. Así se presenta "la alegría del artista en el acto de crear" (79). Sin embargo, esto presenta dos aspectos negativos: en primer lugar, es posible para unos pocos, dotados de esas capacidades artísticas; en segundo lugar, reaparece la objeción propia de la primera técnica: su intensidad aparece "amortiguada por comparación a la que produce saciar mociones pulsionales más groseras, primarias; no conmueven nuestra corporeidad" (79).

Asimismo analiza otra técnica, en la cual "se aflojan aún más los lazos con la realidad" (80): la satisfacción se obtiene a través de ilusiones propias de la vida de la fantasía; allí se ubica el goce de obras de arte, aún para quienes no son artistas. Sin embargo, "la débil narcosis que el arte nos causa no puede producir más que una sustracción pasajera de los apremios de la vida; no es lo bastante intensa para hacer olvidar una miseria objetiva" (80). 
Hallamos, entonces, que aquí se presenta una amplia divergencia con el alcance o profundidad que el arte en términos sociales supone para Freud en comparación con Nietzsche. En efecto, si para ambos implica un dispositivo social de reducción del sufrimiento, para Freud esta reducción es de carácter discreto y de baja intensidad, una 'leve narcosis' que no 'conmueve nuestra corporalidad' (Freud, "El malestar" 79); para Nietzsche, por el contrario, se trata de una reducción de carácter continuo y de eminente intensidad. Así, si en Freud el efecto producido por el arte no es tanto como para "hacer olvidar una miseria objetiva”, en Nietzsche dicho efecto logra redimir el carácter horrible y absurdo de la existencia, permitiendo soportarla a través de sus imágenes. De este modo, en su capacidad de transmutar el carácter penoso de la existencia en soportable, para Nietzsche "el arte es la vocación más importante y la actividad esencialmente metafísica de la vida" (Nietzsche, "El nacimiento" 22), mientras para Freud el arte resulta una técnica de elisión del sufrimiento de poca efectividad -y, en términos de creación, alcanzable para unos pocos-. Es por ello que en El malestar en la cultura es rápidamente dejada de lado para focalizarse en otras técnicas más auspiciosas ${ }^{8}$.

La convergencia en términos de impulso, y la divergencia intensiva planteadas, operan en el campo estético: el plano de la "realidad objetiva" (Freud) y de la "existencia" (Nietzsche) no son transformados en sí desde lo artístico"; ahora bien, dicha relación de externalidad se verá quebrada en Nietzsche, al momento en que -como a continuación se desarrollará- se modifique la relación metafísica entre vida y arte.

8 Esto halla su correspondencia en el despliegue que el arte presenta: en Nietzsche, actúa sobre la totalidad de la polis helénica; en Freud, solamente, alcanza a los artistas y a quienes gozan del arte.

9 La transmutación operada por lo artístico sobre lo 'horrible y absurdo' de la existencia pareciese refutar este planteo en el caso de Nietzsche; sin embargo, dicha operación supone, como se estableció, la creación de imágenes que 'ayuden a soportar la vida'; así, esa existencia vital no se ve transformada en sí, sino que recibe una ayuda, desde el campo de lo estético, para ser soportada. 


\section{Nietzsche: la implosión del campo metafísico}

La perspectiva sobre la relación entre arte y vida se modifica sustancialmente en la producción nietzscheana posterior a El nacimiento de la tragedia, en tanto se genera, centralmente, una ruptura respecto al carácter metafísico tanto del arte como de la vida misma. Así, es en el tercer libro de Humano, demasiado humano, un libro para pensadores libres (Menschliches, Allzumenschliches. Ein Buch für freie Geister) -texto publicado en 1886- donde Nietzsche afirma: "Porque como quiera que sea, con la religión, el arte y la moral no tocamos la esencia del mundo en sí" (Nietzsche, "Humano" 47). ¿Qué ha sucedido? Aquellas actividades humanas -la religión ${ }^{10}$, y más eminentemente, el arteque permitían, al ser metafísicas, redimir y elevar la existencia, resultan ahora inútiles en su tarea; sin embargo, no serán otras actividades las que -en tanto metafísicas- ocupen su lugar: "todo lo que les han producido [a los hombres] las hipótesis metafísicas, temibles, agradables, lo que han creado en ellos, es pasión, error y engaño de sí mismos" (Nietzsche, "Humano"47). Si la metafísica es considerada como error y engaño, entonces no solamente los medios específicos de redención -arte y religión- pierden su lugar y su importancia en tanto tales, sino que la dinámica de descentramiento vital como un proyectarse, a través del ensueño y de la embriaguez, hacia los planos redentores de la forma y de lo informe -el Ür-eine-, desaparece; todo aquello que, en términos de una cultura determinada, fijaba las pautas de engrandecimiento vital, resulta ahora inútil o incluso nocivo, y puesto al lado de la moral: algo que empequeñece la vida.

Ahora bien, la ruptura del carácter metafísico en la relación de la vida con el arte no supone una desaparición de dicha relación sino su modificación profunda. Dicha modificación se articula al modo en que Nietzsche define la verdad:

¿Qué es entonces la verdad? Una hueste en movimiento de metáforas, metonimias, antropomorfismos, en resumidas cuentas, una suma de

10 En efecto, en El nacimiento de la tragedia, Nietzsche afirma: "Ese mismo instinto que da vida al arte como complemento y terminación de la existencia, dio también nacimiento al mundo olímpico (...)" Si el arte es la actividad metafísica "por excelencia", la religión resulta un producto asimismo esencial para la vida -“ ¿Cómo hubiese podido, de otro modo, este pueblo tan delicado (...) soportar la existencia, si no hubiera contemplado en sus dioses la imagen más pura y estimulante?” (34). 
relaciones humanas que han sido realzadas, extrapoladas y adornadas poética y retóricamente y que, después de un prolongado uso, un pueblo considera firmes, canónicas y vinculantes; las verdades son ilusiones de las que se ha olvidado que lo son (...). (Nietzsche, 'Sobre verdad' 208).

Y estas verdades, estas ilusiones de las cuales forman parte las "hipótesis metafísicas", se articulan entonces a un carácter propiamente artístico:

Solo olvidando ese primitivo mundo de metáforas (...) solo al indomablemente creer que este sol, esta ventana, esta mesa son una verdad en sí -en breve, el hombre vive con alguna medida de quietud, seguridad, y consistencia solo al olvidar que es un sujeto, y de hecho un sujeto artísticamente creativo (Nietzsche, "Sobre verdad" 197).

La ruptura de la articulación metafísica entre vida y arte se hace aquí explícita: el arte no resulta ya un medio y una actividad dados para redimir la existencia, al modo en que es concebido en El nacimiento de la tragedia, sino que supone las propias capacidades transformadoras de esa misma existencia. Las verdades a través de las cuales el hombre vive no son sino creaciones que adquieren carácter de verdad solo a través del olvido de su carácter de creación. Así, "la creencia en el mundo que debería ser, es, existe realmente, es una creencia de improductivos que no quieren crear un mundo tal como debe ser. Lo ponen como inexistente, buscan los medios y caminos para llegar a él. 'Voluntad de verdad" como impotencia de la voluntad de crear" (Nietzsche, "Fragmentos" 250).

Desde aquí, hallamos que se mantiene, respecto a El nacimiento de la tragedia, a la actividad artística como fundamental; lo que se modifica profundamente es el carácter de articulación que presenta para con la vida: no se trata ya, entonces, de redimir la existencia, de ser capaz de soportar lo horrible y absurdo de ella -ni tampoco, como aclara el fragmento, de aceptarla tal cual es- sino de tener la potencia para modificarla ${ }^{11}$.

11 Ridley ("Nietzsche on Art") plantea que en El nacimiento de la tragedia la realidad última es incognoscible, aunque aprehensible a nivel metafísico (55 y ss); en Humano, demasiado humano, ciencia y arte se hallan como pares; desde La gaya ciencia, la distinción entre realidad y apariencia comienza a desaparecer; en el mismo sentido, Young sostiene que en El nacimiento la realidad es científicamente incognoscible, 
Ahora bien, ¿cómo es que dicha potencia de modificación presenta carácter específicamente artístico?

Los artistas no deben ver nada tal como es, sino que lo deben ver más pleno, y más simple, y más fuerte de cómo es: para eso han de tener en el cuerpo una especie de primavera y juventud eternas, una especie de ebriedad habitual. (...) Todo arte produce un efecto tónico, aumenta la fuerza, enciende el placer, (es decir, el sentimiento de fuerza), excita todos los más finos recuerdos de la ebriedad. (Nietzsche, "Fragmentos" 557)

La elevación vital que supone la actividad artística se conecta, así, al modo en que era planteado en El nacimiento de la tragedia, con un estado de ebriedad. Ahora bien, este estado de excitación, que aumenta la fuerza y el placer ${ }^{12}$, supone asimismo "no ver nada tal como es". Si tanto aquí como en El nacimiento de la tragedia la capacidad artística implica una modificación de la percepción, aquí dicha modificación supone una capacidad de transformar la existencia misma de las $\operatorname{cosas}^{13}$ : es desde el poder ver las cosas de otra manera que se hace posible transformarlas -que se hace posible la creación- ${ }^{14}$. La modificación, a nivel fisiológico, de la propia percepción, supone una percepción distinta del único mundo en el cual se vive: ya no desde el plano metafísico sino una mirada diversa de la realidad inmanente.

mientras que desde La gaya ciencia el arte resulta necesario desde la perspectiva de conocimiento del mundo (142 y ss). La modificación de perspectiva nietzscheana, como resulta evidente, es tratada siempre desde el plano gnoseológico, y no desde la propia capacidad transformativa que el arte pueda presentar en cuanto a lo existente.

12 Contrario a la postura de Ridley ("What is") que piensa a la capacidad artística en Nietzsche en términos de ideal ascético (186 y ss).

13 Es en este sentido que Jenkins piensa lo 'verdadero' del arte como función de poder (168 y ss).

14 Contraria a la curiosa perspectiva de Pothen que sostiene que Nietzsche piensa con hostilidad y sospecha contra los artistas y el arte en general -el arte, aquí, aparece caracterizado como 'debilidad psicológica' (8). Por el contrario, según se sostiene aquí, el abrazo a la capacidad artística propia del hombre, arrancada del olvido, es lo que potencia su fuerza -sus posibilidades transformativas. 
Si es desde una profunda modificación de la capacidad perceptiva que, en Nietzsche, el arte aparece con capacidad eminentemente transformativa, nos interesará entonces interrogar el modo en que la percepción es conceptualizada en Freud, para desde allí inquirir sobre las limitaciones que, en su perspectiva, el arte presenta en términos transformativos.

\section{Freud: la percepción como recolección de muestras}

En La interpretación de los sueños hallamos una definición de la percepción como parte del aparato psíquico, al cual se le adscribe:

un extremo sensorial y un extremo motor; en el extremo sensorial se encuentra un sistema que recibe las percepciones, y en el extremo motor, otro que abre las esclusas de la motilidad. (...) Ahora bien (...) supondremos que un sistema del aparato, el delantero, recibe los estímulos perceptivos, pero nada conserva de ellos y por tanto carece de memoria, y que tras él hay un segundo sistema que traspone la excitación momentánea del primero a huellas permanentes (530-532)

La percepción aparece así como una función puramente receptora e instantánea, que nada conserva ni modifica: no es sino la entrada de estímulos externos al aparato psíquico que solo supone una modificación a partir de una acción operativa diversa, la de la memoria. La concepción de la percepción en términos de recepción de excitación marca entonces, centralmente, una utilidad determinada:

La recepción de sirve sobre todo al propósito de averiguar la orientación y la índole de los estímulos exteriores, y para ello debe bastar con tomar pequeñas muestras del mundo externo, probarlo en cantidades pequeñas. (...) quizá se lo podría comparar con unas antenas que tantearan el mundo exterior y se retiraran de él cada vez. (Freud, "Más allá" 27-28).

De este modo, la percepción es concebida en términos puramente receptivos. Su función es obtener "muestras del exterior", elementos con los cuales el aparato psíquico laborará posteriormente a través de operaciones transformativas 
como pueden ser las directamente mecánicas (desplazamientos, interacciones varias) o psíquicas, por ejemplo aquellas del sueño que generan sobre algunos de esos elementos percibidos procesos de condensación y desplazamiento.

Desde esta caracterización de la percepción en Freud, es posible entonces retornar a la problemática del arte. Al comparar el carácter del arte en términos de capacidad transformativa social entre Freud y el Nietzsche de El nacimiento de la tragedia, se habían hallado varios puntos de concordancia: el arte suponía una consolación y auto-liberación frente al carácter negativo que presentaba la existencia. Sin embargo, una diferencia de la profundidad de sus efectos se proyectaba: mientras que, en Freud, el arte no resultaba sino "débil narcosis" que no podía hacer olvidar miserias objetivas, en Nietzsche la potencia del arte resultaba tal que era capaz incluso de redimir la existencia misma. Desde allí, el carácter que la percepción cobra en cada pensador resultaba determinante para dar cuenta de dicha divergencia. En efecto, si para Freud la percepción resulta eminentemente receptiva, en Nietzsche la misma presenta un carácter activo y creador que permite, entonces, en su capacidad artística, lograr fundar ese plano de redención de la existencia.

Sin embargo, el carácter de diferenciación del lugar seguía siendo intensivo: si en Freud la miseria objetiva seguía existiendo, antes y después de la débil narcosis del arte, en Nietzsche lo "horrible y absurdo" de la existencia era redimido mas no transformado en sí. Es con la llegada de la ruptura de la relación metafísica entre vida y arte en Nietzsche que la divergencia entre su perspectiva del arte y la freudiana cobra un carácter estructural. La potencia que el arte presentaba en tanto transformadora, roto el dique metafísico, logra desplegarse por sobre lo existente mismo: el hombre es un sujeto artísticamente creativo, capaz de modificar la existencia -en tanto esa misma existencia no es sino "verdad", es decir, ilusión canonizada-. Frente a un mundo exterior freudiano del cual la percepción toma muestras -para luego retirarse- la percepción nietzscheana, por el contrario, avanza sobre un mundo informado a partir de la percepción misma, un mundo -en palabras de Nietzsche, "este sol, esta ventana, esta mesa" - que no es sino metáfora institucionalizada. Desde este doble entrecruce analítico, a saber, el carácter de la percepción y la ruptura de la relación metafísica entre arte y vida en Nietzsche, es posible entonces disponer una divergencia tanto de carácter intensivo como estructural entre las concepciones de Nietzsche y Freud sobre el arte: una arte como "débil 
narcosis" que solamente hace olvidar por unos momentos de la problemática del mundo exterior, frente a una capacidad artística capaz de transformar ese mismo mundo $-\mathrm{y}$ que, por ende, implica la continua potencialidad de reconstrucción de lo social mismo.

\section{Conclusión: la estética, la ética, la vida}

La impronta artística resulta ser diferente en Freud y Nietzsche en cuanto a su alcance, capacidad y carácter. No se trata de que, en Freud, lo artístico no produzca cambios en el mundo exterior: en realidad, el artista logra plasmar sus deseos en el mundo exterior a través de su producción. Ahora bien, dichos logros presentan un carácter eminentemente reactivo: no es a través de la obra artística en sí -del producto artístico- sino desde el rodeo producido por su reconocimiento social que se obtienen esos logros -en términos de Freud, la obtención de, entre otros, mujeres, dinero, fama-. Justamente en tanto se trata de reconocimiento y aceptación social, es que lo obtenido vía la producción artística nunca puede conducir a transformaciones de lo social mismo. Por el contrario, en Nietzsche la creación artística supone en sí transformación del mundo y no una transformación que suponga un reconocimiento dentro de los estándares ya dados sino que, precisamente, modifique a estos últimos. Esta articulación entre status de la percepción y capacidad transformativa artística se ilustra particularmente en el siguiente comentario que Freud realiza en una carta a Karl Abraham, del 26 de diciembre de 1922, refiriéndose a una litografía que el pintor vanguardista Lajos Tihanyi le había realizado:

Es horrible. Sé que es usted excelente persona, por lo que me apena aún más ese pequeño fallo de su carácter que supone la tolerancia o simpatía hacia el 'arte' moderno... El artista declara que le ve así. Las personas como él debieran ser la últimas en tener acceso a los círculos analíticos, pues constituyen la más extrema ilustración de la teoría de Adler, según la cual solo aquellos que padecen graves defectos congénitos de visión llegan a ser pintores o delineantes (Faldezer 461-462)

En la perspectiva freudiana, el arte, como producto de una percepción eminentemente receptiva, recibe título de tal en tanto produce "copias valiosas 
de la realidad objetiva misma"15 (Freud, "Formulaciones" 229). Desde esta concepción mimética del arte, las producciones del movimiento vanguardista ${ }^{16}$ pueden ser - al modo de la litografía de Lajos Tihanyi- concebidas entonces desde dos puntos de vista: o no son arte -pues no toman la forma de la "copia de la realidad"- o son producto de percepciones defectuosas -y entonces resultarían arte, en tanto son "copias", pero defectuosas, horribles. Así, no hay posible apreciación estética positiva de una percepción transformada. Pero, justamente, es a partir de esa percepción transformada que desde el vanguardismo se busca generar una actitud crítica en el espectador, se busca la denuncia y la transformación social ${ }^{17}$. Solo desde el ver de otra manera es posible la generación de cambio -y, así, Nietzsche sostiene que "el artista no debe ver nada como es" (Nietzsche, "Fragmentos" 557). Lo artístico presenta así una potencia intensiva de otro orden: es la capacidad de transformación de las modalidades mismas de existencia. Desde este punto de vista, es válido rescatar elementos del análisis que Lyotard realiza respecto al arte vanguardista:

$15 \mathrm{Al}$ respecto, es esclarecedor cómo Bergstein ('Mirrors') concibe la influencia de la cultura visual en Freud eminentemente a partir de la fotografía (16 y ss). Asimismo, $c f r$. Bergstein ('Freud's').

16 De una carta de Freud a Oskar Pfister, autor de un ensayo sobre el expresionismo: "Comencé a leer su librito sobre el expresionismo con tanto interés como aversión y lo acabé de una sentada... Debo precisar, por otra parte, que en la vida real soy intolerante hacia los chiflados, que veo solo su lado dañino y que en lo que respecta a estos 'artistas', soy casi como aquellos a quienes usted fustiga al principio, considerándolos filisteos e intransigentes. $\mathrm{Y}$, al final, explica usted con claridad y exhaustivamente por qué esa gente no tiene derecho a llamarse artistas" (Meng 77). Sobre el rechazo freudiano por el arte vanguardista, $c f r$. especialmente Cuevas del Barrio (181 y ss).

17 Del ya clásico Teoría de la vanguardia, de Peter Bürger: "La idea de sistema, esencial en el arte clásico, se invierte en la vanguardia en la medida en que no se trata de organizar canónicamente realidades existentes, sino de provocar la emergencia de realidades implícitas. El momento pleno de la vanguardia sería el constructivo, no el crítico, al que a menudo se reduce" (9). En esta línea, Calinescu (98) menciona asimismo a Secante Rodrigues, quien, en su escrito de 1825, "Lartiste, le savant et l'industriel" -que presenta el primer registro conocido del término avant-garde- llama a los artistas a convertirse en la "vanguardia” del pueblo, en tanto 'el poder de las artes' es la forma más veloz para la reforma social y político-económica. 
En la pintura, después de la exploración de las restricciones recaídas en la organización cromática de las superficies, no queda más que el color (las primeras Fenêtres de Delaunay son de 1911). Del mismo modo, en música, el análisis de las regulaciones de la altura no deja por último subsistir como resto más que el material, la enigmática presencia del vibrar. (...) Cézanne decía que la forma se cumple cuando el color alcanza su perfección. Rechazaba de tal modo el principio o prejuicio clásico de la oposición de la forma (la construcción por el dibujo) y la materia (los colores aplicados a continuación sobre las figuras dibujadas), y la prioridad de la primera por sobre la segunda. La materia cromática debe disponerse 'por sí misma', por así decirlo. No recibe una forma. Hace una forma. (175-6)

La capacidad artística, en términos de Nietzsche, supone deshacer las formas de lo existente y generar otras ${ }^{18}$; esto se expresa en el análisis genealógico de los conceptos -análisis desde el cual se deduce que los mismos no son sino construcción, metáfora; así, al analizar el concepto de Schuld ${ }^{19}$ (culpa) -posicionado por Nietzsche en una esfera ético-religiosa- hace derivar al mismo de la noción de schulden (tener deudas), propio de la esfera material del intercambio y lo legal, que a su vez se deriva del placer de hacer sufrir al otro, es decir, se inserta en una suerte de economía del placer y el dolor, propia de un ámbito psicológico-fisiológico. De este modo, el análisis genealógico reconduce al concepto de culpa, en cuanto a su estructura formal, a un resto dispuesto en intensidades fisiológico-psicológicas, a una materialidad que hace a lo corporal. Como en la perspectiva de Lyotard, el deshacer la forma canónica no puede sino conducir a un resto que hace a lo material. El carácter complementario de dicha perspectiva implica la capacidad constructivotransformativa de dichas formas (como señala Lyotard: la materia "no recibe una forma. Hace una forma").

18 Como se había mencionado antes, la teoría darwiniana lo que hace es pasar por alto "la supremacía de principio que poseen las fuerzas espontáneas, agresivas, invasoras, creadoras de nuevas interpretaciones, de nuevas direcciones y formas" (Nietzsche, "Genealogía" 12).

19 Cfr. Nietzsche, 'Genealogía, tratado II especialmente. 
El arte, entonces, resulta estructuralmente definido por Freud y Nietzsche desde una relación de inversión: mientras que el artista es, para Freud, aquel que ve las cosas como son -y por eso produce "copias valiosas"- el artista es, en Nietzsche, aquel que no ha de ver las cosas tal como son, de modo que pueda producir transformación social. Ahora bien, este plano estético-ético es pensable en términos de la caracterización propia de cada autor de la percepción, solamente en tanto esta se halla a su vez articulada a una determinada concepción de un "exterior" percibido y de una vida que esgrime dicha capacidad perceptiva. Si, como se había establecido, en Nietzsche ese mundo exterior -ese sol, esa silla, esa ventana- no son sino metáforas solidificadas -y por tanto, transformablesse debe a una determinada relación que se establece entre las capacidades transformativas y ese exterior. Así, Nietzsche establece, respecto de las teorías biológicas contemporáneas a él, que

se ha definido la vida misma como una adaptación interna, cada vez más apropiada, a las circunstancias externas (Herbert Spencer). Pero con ello se desconoce la esencia de la vida, su voluntad de poder; con ello se pasa por alto la supremacía de principio que poseen las fuerzas espontáneas, agresivas, invasoras, creadoras de nuevas interpretaciones, de nuevas direcciones y formas, por influjo de las cuales viene luego la "adaptación" (...) (Nietzsche, "Genealogía" 12)

Frente a esas circunstancias externas existen potencias internas a lo vital que suponen la capacidad de invadir, modificar, crear nuevas interpretaciones, formas; lo vital es, así, algo que presenta fuerzas capaces de incidir sobre lo externo y transformarlo.

Por otro lado, la relación vital freudiana con ese exterior será otra. En efecto, al referirse Freud a la aparición de los primeros seres vivos, establece que

esta partícula de sustancia viva flota en medio de un mundo exterior cargado (laden) con las energías más potentes, y sería aniquilada por la acción de los estímulos que parten de él si no estuviese provisto de una protección antiestímulo (Reizschutz). (...) Para el organismo vivo, la tarea de protegerse contra los estímulos es casi más importante que la de recibirlos (...) (Freud, "Más allá" 27) 
Así, la relación respecto a ese exterior, en términos de intensidad de fuerzas, presenta prácticamente una inversión respecto a Nietzsche: la hipertrofia energética de esa exterioridad es tal, respecto a las propias fuerzas del viviente freudiano, que antes que nada se trata de establecer una protección frente a sus estímulos. La necesidad de reciprocidad para con el status que la percepción toma, en términos de receptividad, resulta así evidente: para lograr una adecuada capacidad de protección frente a ese exterior, la que percepción busca, antes que nada, tomar "pequeñas muestras del mundo externo" (Freud, "Más allä" 27-28), habrá de tomarlas del modo más exacto posible ${ }^{20}$. Dicho de otra manera, una percepción eficaz en términos vitales -que produzca, antes que nada, una adecuada defensa- habrá de ser aquella que vea las cosas tal cual son.

Esta diversidad opositiva de las capacidades artísticas en Freud y Nietzsche fue articulada al modo en que es conceptualizada, para cada autor, la percepción. Una capacidad receptiva, que ha de ver las cosas como son, en Freud, frente a una capacidad activa, transformativa, que, en el artista, nunca ha de ver las cosas como son, en Nietzsche. Sin embargo, ese carácter que la percepción toma para cada uno había de ser relacionado al modo en que ese exterior mismo, sobre y desde el que se percibe, era concebido. Desde allí, la caracterización de la percepción es comprensible en términos del modo en que ese exterior y lo vital mismo son articulados. Mientras que en Nietzsche las fuerzas activas internas al viviente presentan una "supremacía de principio" (prinzipielle Vorrang) respecto de las fuerzas adaptativas, la tendencia del viviente mismo será asaltar, conformar, crear actuando sobre ese exterior exterior que, entonces, podrá adquirir carácter de "metáfora"; por otro lado, en Freud son las fuerzas del exterior quienes presentan una supremacía en términos de potencia, que hacen de la protección la actividad principal del viviente. Así, resulta perfectamente comprensible la actitud freudiana frente al arte de vanguardia: no se trata de que le choca como algo horrible y defectuoso solamente desde la apreciación estética; le choca en tanto resulta contrario a su propia concepción de vida -y justamente por ello, habla del "lado dañino" que estos presentan, estos que "no tienen derecho a llamarse artistas" (Meng 77).

20 Sin desdeñar, como se estipula en la anterior cita -en tanto se trata de una vida rodeada de estímulos hipertróficos- la función conservativa de la vida que dicha percepción ejerce -y de allí la 'protección antiestímulo', que rebaja la intensidad de las muestras obtenidas. 
Desde aquí, por el contrario, la perspectiva nietzscheana presenta frente a este arte de vanguardia una relación mucho más sintónica ${ }^{21}$.

De este modo, es posible establecer que la divergencia entre Nietzsche y Freud respecto a la perspectiva artística no se sustenta únicamente en el plano estético, sino que la misma se halla atravesada por el plano ético ${ }^{22} \mathrm{y}$-fundamentalmentese despliega a partir de la propia concepción de lo vital que cada uno sostiene ${ }^{23}$ : la priorización de la conservación o de la transformación de lo existente.

\section{Lista de referencias}

Almeida, Rogelio Miranda. Nietzsche e Freud, eterno retorno e compulsão à repetição. São Paulo: Loyola, 2005.

Ansell-Pearson, Keith. Nietzsche and Modern German Thought. London: Routledge, 1991.

Assoun, Paul-Laurent. Freud et Nietzsche. Paris: P.U.F., 2008.

Bergstein, Mary. "Freud's 'Moses of Michelangelo': Vasari, Photography, and Art Historical Practice". The Art Bulletin, 88, 1 (2006): 158-176.

Bergstein, Mary, Gilman, Sander, Makari, George. Mirrors of Memory: Freud, Photography, and the History of Art. New York: Cornell Univ. Press, 2010.

Boothby, Richard. Freud as philosopher, -Metapsychology after Lacan. Londres: Routledge, 2001.

Bürger, Peter. Teoría de la vanguardia. Barcelona: Península, 2000.

Butler, Judith. Mecanismos psíquicos del poder. Madrid: Cátedra, 2010.

21 Al respecto, $c f r$. Kotska, Nietzsche and "An Architecture of Our Minds", en donde se analiza la influencia nietzscheana sobre arquitectos y pintores vanguardistas, como Klimt o Le Corbusier -es decir, donde, justamente, el concepto mismo de percepción resulta central.

22 Desde esta perspectiva es posible enmarcar la propuesta de von Vacano (2007) de generar una política teórica estética a partir de la estética nietzscheana.

23 Para profundizar sobre las concepciones de lo vital en Freud y Nietzsche, $c f r$. Zengotita, "Conflictividad vital: Nietzsche y Freud", Zengotita, "La vida como conflicto en Nietzsche y Freud: cercanías y rupturas políticas con el paradigma inmunitario de Esposito", como también Zengotita, "Derivas sociopolíticas de la conservación y la expansión: la vida misma en Nietzsche y Freud”. 
Calder, William. Musgrave. "El debate Wilamowitz-Nietzsche: nuevos documentos y una reevaluación”. Nietzsche-Studien, 12, (1983): 214-254.

Cuevas del Barrio, Javier. Entre el silencio y el rechazo, Sigmund Freud ante al arte de vanguardias. Málaga: Servicio de Publicaciones de la Univ de Málaga, 2010.

Calinescu, Matei. The Five Faces of Modernity: Modernism, Avant-Garde, Decadence, Kitsch, Postmodernism. Durham: Duke University Press, 1987.

Chapelle, Daniel. Nietzsche and psychoanalysis. Albany: State Univ. of New York Press, 1993.

Drivet, Leandro. "Freud como lector de Nietzsche. La influencia de Nietzsche en la obra de Freud". Civilizar 15, 29 (2015): 197-214.

Faldezer, Erns, (ed.). The Complete Correspondance of Sigmund Freud and Karl Abraham (1907-1925). Londres: Karnac, 2002.

Fernández García, Eugenio. "En torno al malestar: aproximaciones de Nietzsche y Freud”. Mal-Estar Subjetivo. v.1 n.1 (2001): 10-42.

Freud, Sigmund. Obras completas. Buenos Aires: Amorrortu, 1992.

Gay, Peter. Freud. Una vida de nuestro tiempo. Barcelona: Paidós, 1996.

Granier, Jean. "Le statut de la philosophie selon Nietzsche et Freud”, Nietzsche-Studien, 8 (1979): 210-224.

Golomb, Jacob, Santaniello, Weaver, Lehrer, Ronald. Nietzsche and depth psychology. New York: State University of New York Press, 1999.

Hanza, Kathia. "Nec docere neque delectare sed sublimare. Sobre la metáfora de la literatura como sublimación en Freud y Nietzsche”. Estudios de filosofía, 28 (2003): 35-54.

Jenkins, Fiona. "Performative Identity: Nietzsche on the Force of Art and Language".

Nietzsche, Philosophy and the Arts. Kemal, Salim, Gaskell, Ivan, Conway, Daniel. Cambridge: Cambridge University Press, 1998. 162-184.

Kostka, Alexandre, Wohlfarth, Ivan. Nietzsche and "An Architecture of Our Minds". Los Angeles: Getty Research Institute for the History of Art and Humanities, 1999.

Levy Lezcano, Silvia. "Freud y Nietzsche: crónica de un desencuentro". Historia Autónoma (Universidad Complutense de Madrid), 3 (2013): 63-76.

Lyotard, Jean-Francois."Lo sublime y la vanguardia". Lo inhumano. Charlas sobre el tiempo. Buenos Aires: Manantial, 1998. 95-110.

Mann, Thomas. Schopenhauer, Nietzsche, Freud. Madrid: Alianza, 2008.

Meng, Heinrich, Freud, Ernst (ed.). Psychoanalysis and Faith. The Letters of Sigmund Freud and Oskar Pfister. New York: Basic Books, 1962.

Nietzsche, Friedrich. El nacimiento de la tragedia. Madrid: Sánchez Pascual, 2007.

Nietzsche, Friedrich. Humano, demasiado humano. Madrid: Akal, 2007.

Nietzsche, Friedrich. Sobre verdad y mentira en sentido extramoral. Madrid: Península, 2003.

Nietzsche, Friedrich. Fragmentos póstumos, vol. IV. Madrid: Tecnos, 2008.

Nietzsche, Friedrich. Genealogía de la moral. Madrid: Alianza, 2000.

Onfray, Michel. Nietzsche contra Freud. Madrid: Taurus, 2012. 
Pothen, Philip. Nietzsche and the Fate of Art. Aldershot: Ashgate, 2002.

Ridley, Aaron. Nietzsche on Art. London: Routledge, 2007.

Ridley, Aaron. "What is the Meaning of Aesthetic Ideals?". Nietzsche, Philosophy and the Arts. Salim Kemal, Gaskell, Ivan, Conway, Daniel. Cambridge: Cambridge Univ Press, 1998. 185-198.

Reginster, Bernard. The affirmation of life: Nietzsche on overcoming nihilism. Harvard: Harvard Univ. Press, 2006.

Rozitchner, León. Freud y el problema del poder. Méjico DF: Folios, 1982.

Steineger, José. "Friederich Nietzsche and Sigmund Freud failure: a tomist protest on truth". Quodlibet Diary, 6, 1, (2004): 23-38.

Sweet, Dennis. 'The Birth of 'The Birth of Tragedy". Journal of the History of Ideas, 60, 2, (1999): 345-359.

Sokel, Walter. "On the Dionysian in Nietzsche". New Literary History, 36, 4, (2005): 501-520.

Uribe, Darío. Vitalismo cósmico. Bogotá: Siglo del Hombre, 2002.

Von Vacano, Diego. The Art of Power: Machiavelli, Nietzsche, and the Makings of Aesthetic Political Theory. Lanham: Lexinton Books, 2007.

Vázquez Rocca, Adolfo. "La influencia de Nietzsche sobre Freud". Arjé. Revista de

Cultura y Ciencias Sociales, 4 (2005): 22-36.

Vázquez Rocca, Adolfo. "Nietzsche y Freud, negociación, culpa y crueldad: las pulsiones y sus destinos, 'eros' y 'thanatos' (agresividad y destructividad)”. Eikasia, 57 (2014): 67-97.

Young, Julian. Nietzsche's Philosophy of Art. Cambridge: Cambridge Univ. Press, 19

Zengotita, Alonso. "Conflictividad vital: Nietzsche y Freud". Conceptos, creencias y racionalidad. Agüero, G., y Urtubey, L. (Eds). Córdoba: Brujas, 2009. 483-492.

Zengotita, Alonso. "La vida como conflicto en Nietzsche y Freud: cercanías y rupturas políticas con el paradigma inmunitario de Esposito". Revista Mexicana de Opinión Pública, 25 (2018): 83-108.

Zengotita, Alonso. "Derivas sociopolíticas de la conservación y la expansión: la vida misma en Nietzsche y Freud". Revista de Estudios Avanzados de la Universidad de Santiago de Chile, 20 (2013): 75-95. 